American Journal of Applied Sciences 9 (1): 32-39, 2012

ISSN 1546-9239

(C) 2012 Science Publications

\title{
Design of A Microwave Amplifier for Wireless Application
}

\author{
M. Habib Ullah, Badariah Bais, Norbahiah Misran, \\ Baharudin Bin Yatim and M. Islam \\ Department of Electrical Electronics and System Engineering \\ Institute of Space Science (ANGKSA), \\ Universiti Kebangsaan Malaysia, Malaysia
}

\begin{abstract}
Problem statement: Low-Noise Amplifiers (LNA) are very indispensable components in the design of numerous types of communication receivers employed in microwave technology. This paper is presents the design and development of low bias $(\mathrm{Vce}=8 \mathrm{v}$, Ic $=10 \mathrm{~mA})$ single stage low noise microwave amplifier operating in $1.5 \mathrm{GHZ}$ frequency range, Gain $13 \mathrm{~dB} \pm 0.5 \mathrm{~dB}$, input/output return loss $<-10 \mathrm{~dB}$, noise figure $\leq 2.0 \mathrm{~dB}$ and used of Agilent AT-41486 bipolar junction transistor. Approach: The principal design target is to obtain a minimum noise figure while concomitantly achieving a maximum gain by presenting the optimum noise impedance $\left(\mathrm{Z}_{\mathrm{opt}}\right)$ which is characteristically implemented by adding a matching circuit between the source and the input of the amplifier. Results: The proposed low-noise amplifier for microwave wireless application is designed, simulated and optimized using Serenade Harmonica (by Ansoft Corporation) and Advance Design System (ADS) software by Agilent. Conclusion: In this paper a low-noise amplifier operated at 1.5 GHz. is designed because of the significant roles played in the field of microwave communication technology, which includes the application in the output stage of a transmitter where the signals needs to be strengthen before transmission.
\end{abstract}

Key word: Low noise amplifier, noise figure, gain loss, microwave wireless application, maximum gain, low bias, return loss

\section{INTRODUCTION}

The demand for compact, low cost and high gain low noise amplifiers has increased significantly for the antenna design with the wide spread proliferation of wireless communication technology in recent years (Islam et al., 2009a; 2009b; 2009c; 2009d; 2010a; 2010b; 2010c; 2010d; 2011; Mobashsher et al., 2010; Shakib et al., 2010a; 2010b Azim et al., 2010; Faruque et al., 2010; 2011). The trend and revolution of communication technology is increasing day by day, particularly wireless communication. Thus, it becomes competitive technology for radio transceiver implementation of various wireless communication systems, due to technology scaling, high level of integrity and lower cost (Momani et al., 2011).

Recently the demand for both higher data rates and more reliable wireless communications in severe multipath fading is rapidly increasing (Ullah et al., 2009a; 2009b). In a typical radio receiver, low-noise amplifier is one of the essential components in the communication system as it tends to dominate the sensitivity. The fundamental design goal of low-noise amplification is to obtain maximum excellent gain while simultaneously minimizing the noise. Bipolar transistors are often used in the design practice. Because of the inherent characteristics of these transistors, it is relatively difficult to achieve low noise and maximum gain simultaneously. Therefore, tradeoffs have to be made in order to attain acceptable require low noise and appropriate gain results. The reduction in the signal due to power dissipation in circuit components and losses during transmission, reception should be compensated by using a device that will provide satisfactory gain for the receiver circuit.

\section{MATERIALS AND METHODS}

Transistor selection and stability: Careful selection of proper transistor is a very significant stage in the design of low-noise amplifier. The bias point is chosen to keep the transistor operating in active mode using different forms of circuit techniques. Prior to designing a circuit,

Corresponding Author: Habib Ullah, Department of Electrical, Institute of Space Science (ANGKSA),

Electronics and System Engineering University Kebangsaan Malaysia, Malaysia 
it is essential to check whether the active device which is going to use is unconditionally stable or conditionally stable. This is necessary because different conditions require the appropriate design method. It is possible to calculate potentials instabilities in transistors even before an amplifier is built. This calculation serves as a useful aid in finding a suitable transistor for a particular application. Among the goals of the designer is to achieve unconditional stability of the circuit. Unconditional stability means that any load present at the output of the device the circuit will not oscillate. Nevertheless sparameters will aid in the stability analysis. Additionally, in order to find/calculate the stability of a transistor with sparameter, the intermediate quantity (Ds) should calculate first (Huang et al., 1998) Eq. 1 and 2:

$\mathrm{D}_{\mathrm{s}}=\mathrm{S}_{11} \mathrm{~S}_{22}-\mathrm{S}_{12} \mathrm{~S}_{21}$

$$
\mathrm{K}=\frac{1+\left|\mathrm{D}_{\mathrm{s}}\right|^{2}-\left|\mathrm{S}_{11}\right|^{2}-\left|\mathrm{S}_{22}\right|^{2}}{2\left|\mathrm{~S}_{12}\right|\left|\mathrm{S}_{21}\right|}
$$

The Rollet stability factor $(\mathrm{K})$ can be given as eq. (2). If $\mathrm{K}$ is greater than $1(\mathrm{~K}>1)$, then the device (transistor) will be unconditionally stable for any combination of source and load impedances. If $\mathrm{K}<1$, the device is potentially unstable and will most likely oscillate with certain combination of source and load impedances. Nonetheless, if $\mathrm{K}<1$, there are several approaches and steps can be taken to complete the design. Such as, Select another bias point of the transistor or choose a different transistor (Sheng, 1991).

Maximum Available Gain (MAG): The maximum gain can ever achieve from a transistor under conjugately matched conditions is called the Maximum Available Gain (MAG). Maximum available gain is calculated in two steps:

First, calculate an intermediate quantity B1, Eq. 3:

Where:

$\mathrm{B}_{1}=1+\left|\mathrm{S}_{11}\right|^{2}-\left|\mathrm{S}_{22}\right|^{2}-\left|\mathrm{D}_{\mathrm{s}}\right|^{2}$

Secondly, calculate MAG using Eq. 4:

$\mathrm{MAG}=\frac{10 \log \left|\mathrm{S}_{22}\right|}{\left|\mathrm{S}_{22}\right|}+10 \log \left|\mathrm{K} \pm \sqrt{\mathrm{K}^{2}-1}\right|$

where, $\mathrm{K}=$ stability factor from Eq. 5 .

Signals-to-Noise Ratio (SNR): Noise levels must always be less than the required signal; otherwise the required signal will be lost in noise. Some means must be provided to specify the level of the signal above noise. This means is referred as the signal-to-noise ratio. It can be defined mathematically as follows (Shaeffer and Lee, 1997):

$$
\frac{\mathrm{S}}{\mathrm{N}}=\frac{\text { Signal Power }}{\text { Noise Power }}
$$

Noise figure: Certain amplifiers have more inherent electrical noise than others. Manufacturers usually produce a batch of transistors, then classify and name the transistors according to their inherent electrical noise levels. The inherent noise produced by a transistor is dependent on its general operating conditions, particularly temperature, frequency, voltage and operating current and these conditions must be specified when it is noise level is measured Fig. 1 and 2. Mathematically noise figure can be defined as Eq. 6:

$\mathrm{NF}=\frac{\left(\frac{\mathrm{S}}{\mathrm{N}}\right)_{\text {in }}}{\left(\frac{\mathrm{S}}{\mathrm{N}}\right)_{\text {out }}}($ at $290 \mathrm{~K})$

If a transistor introduces no noise, then it's $\mathrm{S} / \mathrm{N}$ at both the inputs and output is the same, therefore from the above equation $\mathrm{NF}=1$ or in $\mathrm{dB} \mathrm{NF}=10 \log 1=$ OdB. Hence, a perfect or noiseless amplifier has a noise figure of $0 \mathrm{~dB}$. An imperfect amplifier has a noise figure greater than $0 \mathrm{~dB}$, for instance an amplifier with a noise figure of $3 \mathrm{~dB}(=2$ ratio), means that, it's twice as bad as perfect as a perfect amplifier (Xion et al., 2007).

\section{Designing using s-parameters:}

S-parameters: Scattering or s-parameters are useful design aids that most manufacturers supply for their high frequency transistors-parameters are widely used because of their ease to measure and work with than Yparameters, they are easy to comprehend, convenient and provide a wealth of information at a glance.

Comparing with y-parameter: While y-parameter utilize input and output voltages and currents to characterize the operation of the two port network, sparameter used normalized incident and reflected traveling waves at each network port. However, with sparameter, there is no need to present a short circuit to the two-port device. Instead, the network is always terminated in the characteristic impedance of the measuring system. 


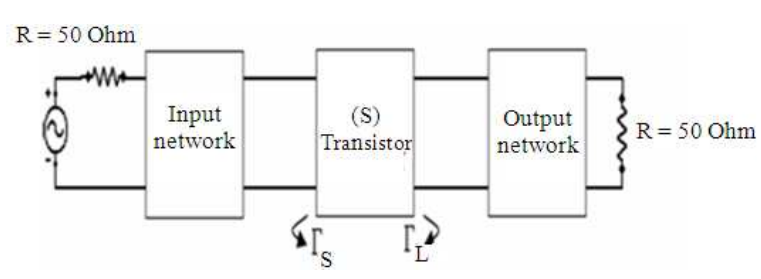

Fig. 1: Block diagram of a typical Low-Noise Amplifier

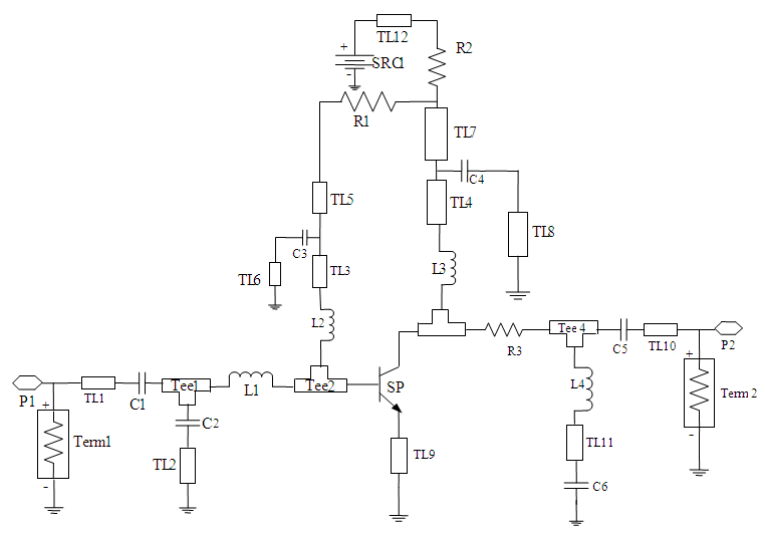

Fig. 2: Schematic diagram of LNA design

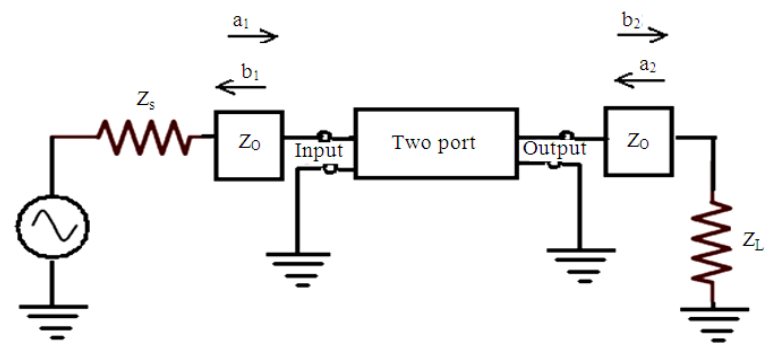

Fig. 3: S-parameters and the Two-Port Network

S-parameters and the two-port network: Inserting two-port network between the source and the load in the circuit of Fig. 3, this yield the circuit of figure above. The following can be deducted from any traveling wave that originates at the source.

A portion of the wave originating from the source and incident upon the two-port device $a_{1}$ will be reflected $b_{1}$ and another portion will be transmitted through the two- port device. A fraction of the transmitted signal is then reflected from the load and becomes incident upon the output of the two-port network $a_{2}$. A portion of the signal $a_{2}$ is then reflected from the output port back toward the load $b_{2}$, while a fraction is transmitted through the two-port device back to the source. It is observed from the above discussion that any traveling wave present is made up of two components, for instance the total traveling wave component flowing from the output of the two-port device to the load is actually made up of that portion of $a_{2}$ which is reflected from the output of the two-port device, plus the portion of $a_{1}$ that is transmitted through two-port device (Wing-Tai et, al. 2006).

Similarly the total traveling wave flowing from the input of the two-port device back toward the source is made up of that portion of $a_{1}$ that is reflected from input port plus that fraction of $\mathrm{a}_{2}$ that is transmitted through the two-port device. From the above observations in equation form, as follows Eq. 7 and 8:

$\mathrm{b}_{1}=\mathrm{S}_{11} \mathrm{a}_{1}+\mathrm{S}_{12} \mathrm{a}_{2}$

$\mathrm{b}_{2}=\mathrm{S}_{21} \mathrm{a}_{1}+\mathrm{S}_{22} \mathrm{a}_{2}$

Where:

$\mathrm{S}_{11}=$ input reflection coefficient,

$\mathrm{S}_{12}=$ reverse transmission coefficient,

$\mathrm{S}_{21}=$ forward transmission coefficient and

$\mathrm{S}_{22}=$ output reflection coefficient

From Eq. 7 and 8 following parameters can be determined as follows Eq. 9:

$S_{11}=\left.\frac{b_{1}}{a_{1}}\right|_{a_{2}=0}$

This is reflected wave divided by an incident wave and therefore by definition is equal to input reflection coefficient. Thus, $S_{11}$ can be plotted on a smith chart and the input impedance of the two-port device can be found.

This is also a reflection coefficient and can be plotted on a smith chart. Similarly the other 2 parameters as follows Eq. 10-12:

$\mathrm{S}_{22}=\left.\frac{\mathrm{b}_{2}}{\mathrm{a}_{2}}\right|_{\mathrm{a}_{1}=0}$

$S_{21}=\left.\frac{b_{2}}{a_{1}}\right|_{a_{2}=0}$

$S_{12}=\left.\frac{b_{1}}{a_{2}}\right|_{a_{1}=0}$

The significance of $S_{21}$ and $S_{12}$ in the equation 1314 are simply forward and reverse gain (or loss) of the two port network respectively, when the two-port device is terminated in the characteristic impedance of the measuring system.

S-parameters, are simply a convenient method of presenting the characteristic impedances of a device to a potential user most of the time the manufacturer will publish both set of parameters along with their variation in frequency, to give the designer the flexibility of working with the parameters with which he feels more comfortable. 


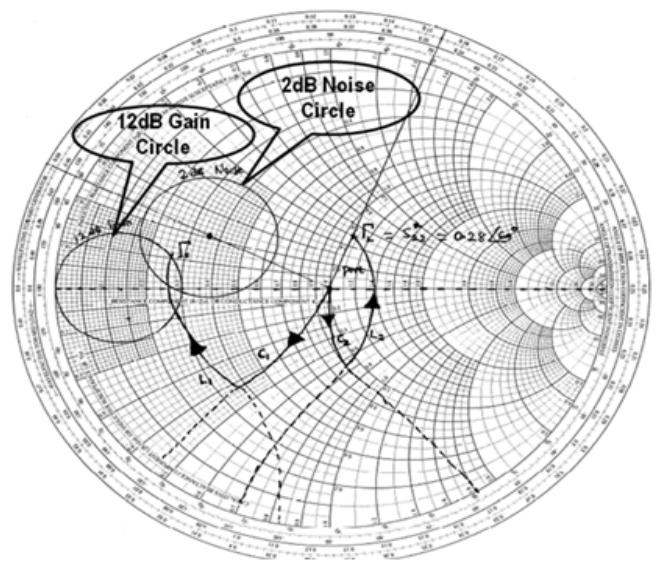

Fig. 4: Smith chart showing noise and gain circles

Design of amplifier for specific gain: in a situation where a specific gain is required, it is normal practice to provide selective mismatching so that transistor gain can be reduced to the desired gain. Selective mismatching is a relatively inexpensive method used to decreased gain by not matching a transistor to its conjugate load. For instance, any of the infinite number of impedances located on the circumference of $12 \mathrm{db}$ constant gain circle would force the amplifier stage gain to $12 \mathrm{db}$.once the circle is drawn on a smith chart; the load impedances can be observed that will provide a desired gain.

Constant gain circles: To plot a constant gain circles on a smith chart, it is necessary to: Where the center of the circle is located and the radius of the circle:

$\mathrm{D}_{2}=\left|\mathrm{S}_{22}\right|-\mathrm{D}_{5} \mathrm{~S}_{11}$

The procedure for calculating a constant gain circles is as follow Eq. 13-15:

$\mathrm{G}=\frac{\text { DesiredGain }}{\left|\mathrm{S}_{22}\right|^{2}}$

Noise circle (2dB):

$$
\begin{aligned}
& \mathrm{N}_{\mathrm{i}}=\frac{\mathrm{NF}_{\mathrm{i}}-\mathrm{NF}_{\mathrm{min}}}{4 \cdot \mathrm{r}_{\mathrm{n}}} *\left|1+\Gamma_{\text {opt }}\right|^{2}= \\
& \frac{10^{\frac{2}{3}}-10^{\frac{1.5}{10}}}{4 * 1.5} * \mid 1+0.48 \angle 134^{0} \\
& \mathrm{I}^{2}=0.28 * \mid 1+\left(-0.33+\left.\mathrm{j} 0.35\right|^{2}\right.
\end{aligned}
$$

(Convert noise parameters to linear units) $=0.28 * 1$ $\left.0.76 \angle 27.6^{\circ}\right|^{2}=0.162$ (Convert back to polar form) Eq. 16-20:
Center of noise circle:

$$
\mathrm{C}_{\mathrm{Fi}}=\frac{\Gamma_{\mathrm{opt}}}{1+\mathrm{N}_{\mathrm{i}}}=\frac{0.48 \angle 134^{\circ}}{1+0.162}=0.413 \angle 134^{\circ}
$$

Radius of noise circle:

$$
\begin{aligned}
& \mathrm{R}_{\mathrm{Fi}}=\frac{1}{1+\mathrm{N}_{\mathrm{i}}} * \sqrt{\mathrm{N}_{\mathrm{i}}^{2}+\left(1-\left|\Gamma_{\text {opt }}\right|^{2}\right)} \\
& =0.86 \sqrt{ } 0.026+0.126=0.334
\end{aligned}
$$

Gain circle (12dB):

$$
\mathrm{g}_{\mathrm{a}}=\frac{\mathrm{G}_{\mathrm{A}}}{\left|\mathrm{S}_{21}\right|^{2}}
$$

$\mathrm{g}_{\mathrm{a}}=1.76$ (where $\mathrm{G}_{\mathrm{A}}$ is desired gain in linear units) from Eq. 1: $D_{\mathrm{s}}=\mathrm{S}_{11} \mathrm{~S}_{22}-\mathrm{S}_{12} \mathrm{~S}_{21} \mathrm{D}_{\mathrm{s}}=0.1 \angle-53, \mathrm{C}_{\mathrm{i}}=\mathrm{S}_{11^{-}}$ $\mathrm{D}_{\mathrm{s}} \mathrm{S}_{22}{ }^{*}=0.64 \angle 179^{\circ}$ from Eq. 2 : $\mathrm{K}=1.04$ :

$$
\begin{aligned}
& \mathrm{R}_{\mathrm{a}}=\frac{\sqrt{\left[\left.|1-2 \mathrm{~K}| \mathrm{S}_{21} \mathrm{~S}_{12}\left|\mathrm{~g}_{\mathrm{a}}+\right| \mathrm{S}_{21} \mathrm{~S}_{12}\right|^{2} \mathrm{~g}_{\mathrm{a}}{ }^{2}\right]}}{\mid 1+\mathrm{g}_{\mathrm{a}}\left(\left|\mathrm{S}_{11}\right|^{2}-\left|\mathrm{D}_{\mathrm{s}}\right|^{2}\right)} \\
& \mathrm{R}_{\mathrm{a}}=0.3
\end{aligned}
$$

Center of gain circle $(\mathrm{Ca})$ :

$$
\begin{aligned}
& \mathrm{C}_{\mathrm{a}}=\frac{\mathrm{g}_{\mathrm{a}} \mathrm{C}_{1}}{1+\mathrm{g}_{\mathrm{a}}\left(\left|\mathrm{S}_{11}\right|^{2}-\left|\mathrm{D}_{\mathrm{s}}\right|^{2}\right)} \\
& \mathrm{C}_{\mathrm{a}}=0.69 \text { Đ-179 }
\end{aligned}
$$

So, the noise and gain circles can be plotted on the smith chart and the $\Gamma$ point selected from the circle overlap region, note that, the radius of the circles and linear position of the circle centers are given as smith chart radiuses and should be plotted using a pair of compasses as shown in the Fig. 4. In this design it is assumed that the unilateral case, i.e., $S_{12}=0$. It is observed from the smith chart, that the elements either follow noise or gain constant resistance circle. To convert the reactance values into component values the following equations should be used. The elements either follow a red or blue constant resistance circle. if a red constant resistance circle cross red constant reactance lines and therefore takes values from the red lines and the same with blue circles and lines is shown Fig. 5. The number 50 in each equation de-normalizes the reactance values:

Arc $\mathrm{C}_{1}=$ Shunt $\mathrm{C}_{1}=1.4$, Arc $\mathrm{L}_{1}=$ Series $\mathrm{L}_{1}=0.65$ Arc $\mathrm{C}_{2}=$ Series $\mathrm{C}_{2}=0.6$, Arc $\mathrm{L}_{2}=$ Shunt $\mathrm{L}_{2}=0.87$ 
Am. J. Applied Sci., 9 (1): 32-39, 2012

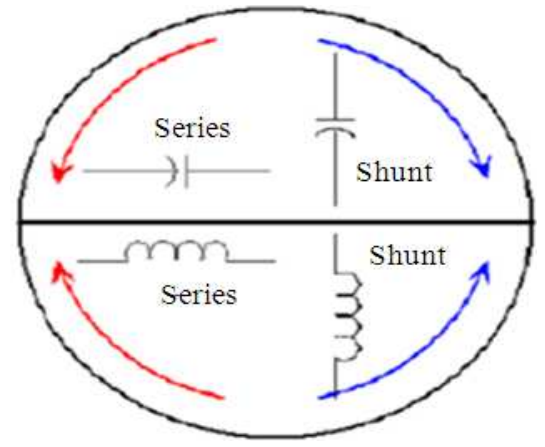

Fig. 5: Series and shunts components

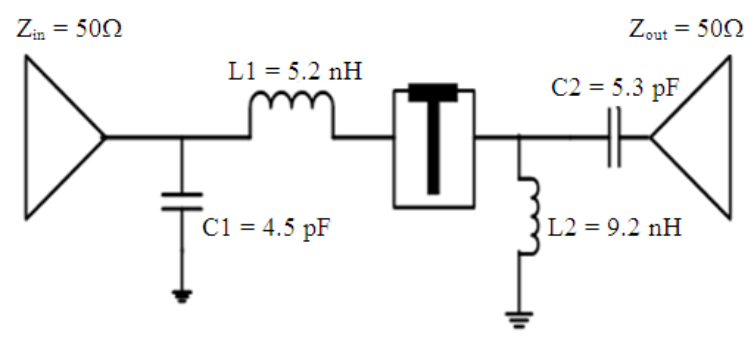

Fig. 6: Components configuration circuits

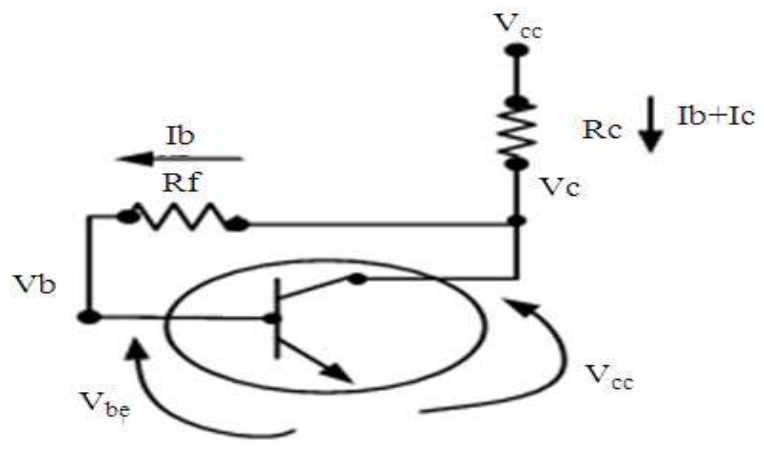

Fig. 7: Feedback bias circuit

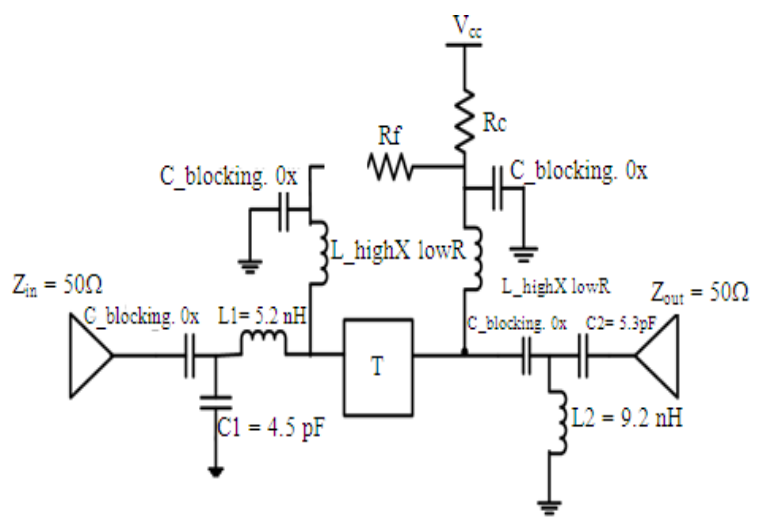

Fig. 8: Low-pass filter circuit
Table 1: The expected/targeted and simulation/obtained results

\begin{tabular}{llll}
\hline SL No. & Parameters & $\begin{array}{l}\text { Obtained result @ } \\
1.5 \mathrm{GHz} \text { scale }(\mathrm{dB})\end{array}$ & $\begin{array}{l}\text { Expected } \\
\text { result }(\mathrm{dB})\end{array}$ \\
\hline 1 & $\mathrm{NF}_{\min }$ & $1.618 \mathrm{~dB}$ & $\leq 2.0 \mathrm{~dB}$ \\
2 & $\mathrm{~S} 11$ & $-7.90 \mathrm{~dB}$ & $\leq-9.0 \mathrm{~dB}$ \\
3 & $\mathrm{~S} 12$ & $-8.80 \mathrm{~dB}$ & $\leq-9.0 \mathrm{~dB}$ \\
4 & $\mathrm{~S} 21$ & $-8.50 \mathrm{~dB}$ & $\geq-9.0 \mathrm{~dB}$ \\
5 & S22 & $-7.8 \mathrm{~dB}$ & $\leq-9.0 \mathrm{~dB}$ \\
6 & Voltage gain & $14.15 \mathrm{~dB}$ & $13 \pm 0.5 \mathrm{~dB}$ \\
7 & VSWR & $2.11 \mathrm{~dB}$ & $\leq 2.0 \mathrm{~dB}$ \\
\hline
\end{tabular}

$$
\begin{array}{ll}
\mathrm{C}_{1} & =1.4 /\left(2 \Pi * 1 * 10^{9}\right) .50=4.5 \mathrm{pF} \\
\mathrm{L}_{1} & =0.65 * 50 /\left(2 \Pi .1 * 10^{9}\right)=5.2 \mathrm{mH} \\
\mathrm{C}_{2} & =1 /\left(2 \Pi^{*} 1 * 10^{9} * 0.6 * 50\right)=5.3 \mathrm{pF} \\
\mathrm{L}_{2} & =50 /\left(2 \Pi * 0.87 * 1 * 10^{9}\right)=9.2 \mathrm{mH}
\end{array}
$$

At the instant, it has all the matching parameters, which can calculate the values for the components (shown on the smith chart) and draw the schematic of the matching networks, it should start from the center of the smith chart (port 1or port 2) and work towards the devices, drawing each element in its correct position and configuration, as shown in the Fig. 6 .

Finally, in order to complete the circuit, it needs to bias the device for low noise (hence, low current operation) which can use a simple feedback bias circuit using two resistor as shown in Fig. 7 and low-pass filter circuit is shown in Fig. 8.

Therefore, all the ideal components values for building the amplifier has obtained. It should be borne in mind that there will be a need for DC blocking capacitors in the RF path, in addition to the capacitors used in the matching network, to prevent DC from finding its way to either of the ports or to ground.

This capacitor will have quite a large value $(\mathrm{nF})$ and is called a zero capacitor due to its very low reactance at RF.

\section{RESULTS}

Simulation result of the proposed design is presented. Figure 9 (from a-g) are shown the sparameter (S11, S21, S12, S12), VSWR of $2.12 \mathrm{~dB}$, Noise Figure of $1.618 \mathrm{~dB}$ and Maximum voltage gain of $14.15 \mathrm{~dB}$.

From the simulation result it is observed that, values of the parameters are closed to expected outcomes. The obtained results are acceptable to design an efficient $1.5 \mathrm{GHz}$ LNA. Table 1 is shown the comparison between expected and obtained result.

\section{DISCUSSION}

The preceding design acquiesce a very low noise figure $\mathrm{NF}_{\text {min }}$, nonetheless the match input is 
underprivileged and the gain $G$ should also be considered. However, the increase in gain and matched can only be attain by connecting the requirements on the noise figure $\mathrm{NF}_{\min }$ so one can decide from a better range of potential input impedances, for this design a noise figure of $\mathrm{NF}_{\min } \leq 2 \mathrm{~dB}$ is required. Yet, draw the noise circle for $\mathrm{NF}_{\min } \leq 2 \mathrm{~dB}$ as shown in the Fig. 3. in order to appreciate both the gain and noise requirements

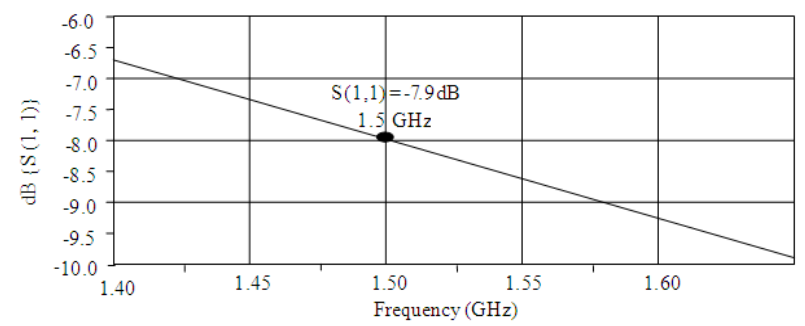

(b)

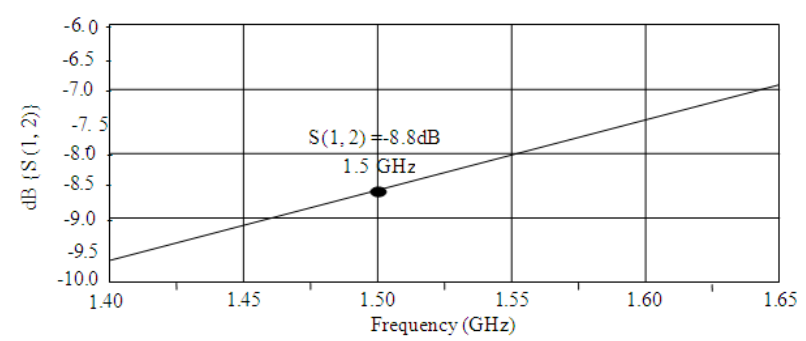

(c)

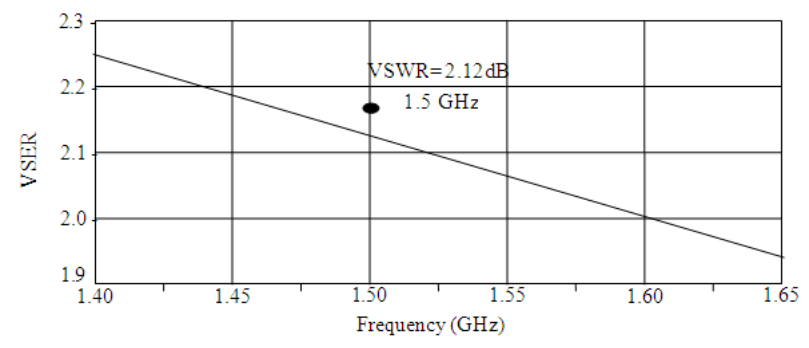

(e) an impedance should be selected that lies within both circles, for this design an available gain of $\mathrm{G}_{\mathrm{a}}=12 \mathrm{~dB}$, this fixes the input reflection coefficient $\left(S_{11} *\right)$. While determining the input reflection coefficient $S_{11}$ draw a power gain circles, state the same gain as for the available gain $G_{a}$ circle, all impedances on this circles direct to the particular specified gain. The matching has to be addressed subsequently.

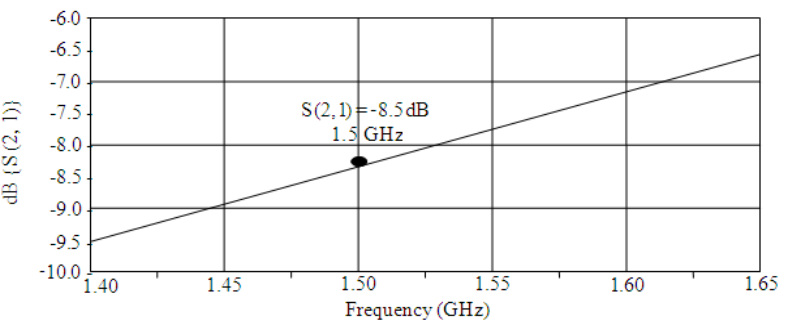

(b)

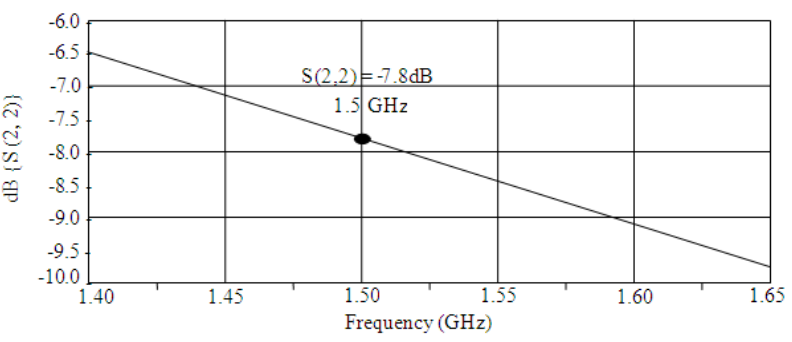

(d)

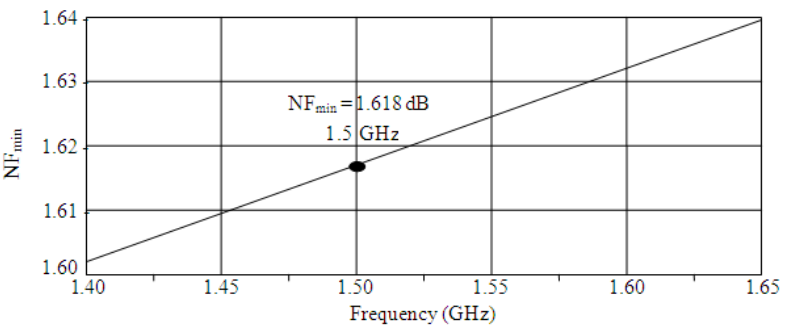

(f)

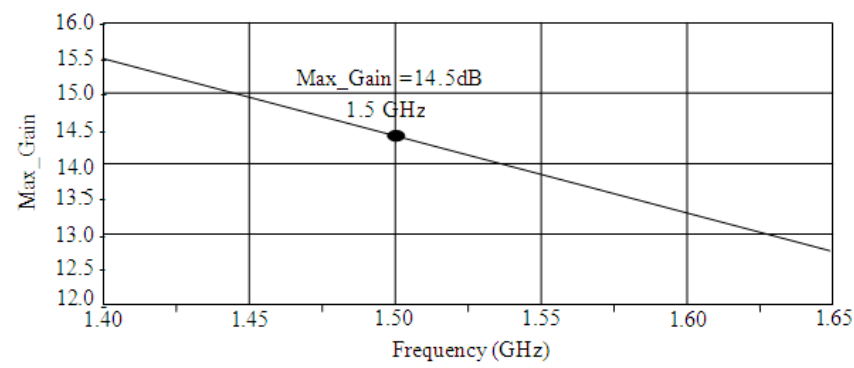

(g)

Fig. 9(a): Simulation result of S-parameter S $(1,1)$ b $(2,1)$ c $(1,2)$ d $(2,2)$ e VSWR (f): Simulation result of Noise Fig. $(\mathrm{g})$ : Simulation result of maximum gain 


\section{CONCLUSION}

The purpose of this manuscript is to design, simulate RF low-noise amplifier operated at $1.5 \mathrm{GHz}$. It has a significant application in the output stage of a transmitter where the signal needs to be strengthening before it is transmission

From the design parameters and simulation result it is anticipated that a $1.5 \mathrm{GHz}$ Low noise amplifier can be designed for RF/Microwave oriented application which targets the suitable maximum gain and a desired noise figure. The approach explained the scattering or s-parameters as a design aid and using the smith chart plots to identify the largest achievable constant gain circle that will meet up the preferred constant noise figure circle. The proposed approach is shown to be very precise in designing microwave low noise amplifier that is often used in communication system.

\section{REFERENCES}

Azim, R., M.T. Islam and N. Misran, 2010. Printed planar antenna for wideband applications. J. Infrared, Millimeter Terahertz Waves, 31: 969-978. DOI: $10.1007 / \mathrm{s} 10762-010-9655-7$

Faruque, M.R.I., M.T. Islam and N. Misran, 2010. Evaluation of Specific Absorption Rate (SAR) reduction for PIFA Antenna using Metamaterials. Frequenz, 64: 144-149. DOI: 10.1515/FREQ.2010.64.7-8.144

Faruque, M.R.I., M.T. Islam, N. Misran, 2011. Analysis of electromagnetic absorption in mobile phones using metamaterials. Electromagnetics, 31: 215232. DOI: $10.1080 / 02726343.2011 .558457$

Huang, Q., P. Orsatti and F. Piazza, 1998. Broadband, $0.25 \mu \mathrm{m}$ CMOS LNAs with sub-2dB NF for GSM applications. Proceedings of the IEEE Custom Integrated Circuits Conference, May 11-14, IEEE Xplore Press, Santa Clara, CA, USA., pp: 67-70. DOI: 10.1109/CICC.1998.694908

Islam, M.T., A.T. Mobashsher and N. Misran, 2010a. Design of microstrip patch antenna using novel Ushaped feeding strip with unequal arm. Elect. Lett., 46: 968-970. DOI: 10.1049/el.2010.0409

Islam, M.T., A.T. Mobashsher and N. Misran, 2010b. A novel feeding technique for a dual band microstrip patch antenna. IEICE Trans. Commun., 9: 24552457. DOI: $10.1587 /$ transcom.E93.B.2455

Islam, M.T., A.T. Mobashsher and N. Misran, 2010c. Coplanar waveguide fed printed antenna with compact size for broadband wireless applications. J. Infrared Millimeter Terahertz Waves, 31: 14271437. DOI: 10.1007/s10762-010-9728-7
Islam, M.T., M.R.I. Faruque and N. Misran, 2010d. Study of Specific Absorption Rate (SAR) in the human head by metamaterial attachment. IEICE Elect. Express, 7: 7240-246. DOI: 10.1587/elex.7.240

Islam, M.T., M.R.I. Faruque and N. Misran, 2011. SAR reduction in a muscle cube with metamaterial attachment. Applied Phys. A: Mater. Sci. Process., 103: 367-372. DOI: 10.1007/s00339-011-6342-z

Islam, M.T., M. Moniruzzaman, N. Misran and M.N. Shakib, 2009a. Curve fitting based particle swarm optimization for UWB patch antenna. J. Electromag. Waves Appli., 23: 2421-2432.

Islam, M.T., M.N. Shakib and N. Misran, 2009b. Multislotted microstrip patch antenna for wireless communication. Progress Electromag. Res. Lett., 10: 11-18. DOI: 10.2528/PIERL09060704

Islam, M.T., M.R.I. Faruque and N. Misran, 2009c. Design analysis of ferrite sheet attachment for sar reduction in human head. Progress Electromag. Res. , 98: 191-205. DOI: 10.2528/PIER09082902

Islam, M.T., M.N. Shakib and N. Misran, 2009d. Modified E-H shaped microstrip patch antenna. IEICE Elect. Express, 6: 1350-1354. DOI: 10.1587/elex.6.1350

Xion, J., G. Hu and A. Qu, 2007. Automatic calibration of frequency compensation system in computercontrolled patch-clamp amplifier. J. Comput. Sci., 3: 765-772. DOI: 10.3844/jcssp.2007.765.772

Ullah, M.H., M.A. Hasan, M.J. Uddin and A.U. Priantoro, 2009a. VHDL modeling of optimum measurement selection by using genetic algorithm. Aus. J. Basic Applied Sci., 3: 3283-3290.

Ullah, M.H., P.A. Unggul, H.M. Asraful and U.M. Jasim, 2009b. FPGA implementation of light rail transit fare card controller using VHDL. Eur. J. Sci. Res., 38: 30-40.

Mobashsher, A.T., M.T. Islam and N. Misran, 2010. A novel high-gain dual-band antenna for RFID reader applications. IEEE Antennas Wireless Propagation Lett., $\quad$ 9: $\quad 653-656 . \quad$ DOI: 10.1109/LAWP.2010.2055818

Momani, M.A., T.A.A. Smadi, F.M.A. Taweel and K.A. Ghaidan, 2011. GPS ionospheric total electron content and scintillation measurements during the October 2003 magnetic storm. Am. J. Eng. Applied Sci., 4: 301-306. DOI: 10.3844/ajeassp.2011.301.306

Shaeffer, D.K. and T.H. Lee, 1997. A 1.5-V, 1.5-GHz CMOS low noise amplifier. IEEE J. Solid-State Circ., 32: 745-758. DOI: 10.1109/4.568846

Shakib, M.N., M.T. Islam and N. Misran, 2010a. High gain W-shaped microstrip patch antenna. IEICE Elect. Express, 7: 1546-1551. DOI: 10.1587/elex.7.1546 
Shakib, M.N., M.T. Islam and N. Misran, 2010b. Stacked patch antenna with folded patch feed for ultra-wideband application. IET Microwaves Antennas Propagation, 4: 1456-1461. DOI: 10.1049/iet-map.2009.0257

Sheng, N.H., 1991. A $30 \mathrm{GHz}$ bandwidth AlGaAsGaAs HBT directcoupled feedback amplifier. IEEE Microwave Guided Wave Lett., 1: 208-210. DOI: $10.1109 / 75.84589$
Wing-Tai, C. and N. Wong, 2006. Optimized RF CMOS low noise amplifier design via geometric programming. Proceedings of the International Symposium on Intelligent Signal Processing and Communications, Dec. 12-15, IEEE Xplore Press, Yonago, pp: 423-426. DOI: 10.1109/ISPACS.2006.364919 